\title{
EMPLOYMENT POLICY FOR LABOUR MOBILITY IN ASEAN ECONOMIC COMMUNITY: CHALLENGING OPPORTUNITIES FOR VIETNAM
}

\author{
Nguyen Duc Huu (Ph.D.) \\ Social work Faculty, Vietnam Trade Union University \\ DOI: https://doi.org/10.51193/IJAER.2021.7309
}

\begin{abstract}
The ASEAN Economic Community (ASEAN Economic Community - AEC) is a regional economic bloc of the 10 ASEAN member states officially established on December 31, 2015, when the establishment declaration officially takes effect. AEC is one of the three important pillars of the ASEAN Community to realize the objectives set out in Vision ASEAN 2020. The two remaining pillars are: ASEAN Security Community and ASEAN Socio-Cultural Community. The ASEAN Economic Community was established to fulfill the ultimate goal of economic integration in "ASEAN Vision 2020", to form a stable, prosperous and highly competitive ASEAN economic region. In which, goods and services, investment will be freely circulated and capital flows more freely, economic development is equal, poverty and socioeconomic gap is reduced in 2020. Over the past years, Vietnam has participated in developing the AEC in a spirit of initiative, positive and responsible. Promoting the establishment of AEC has always been one of Vietnam's highest priorities in the process of international economic integration. This article analyzes the opportunities and challenges of Vietnam when joining this community, especially in the area studies.
\end{abstract}

Keywords: Labor, mobility, employment policy, gender

\section{INTRODUCTION}

In the ASEAN Vision 2020, passed in December 1997, ASEAN leaders have oriented ASEAN to form a Community, which will create a stable, prosperous, highly competitive ASEAN Economic Region in which goods, services and investments are flowing openly, which is more openly flowing, the economy develops evenly, poverty and socio-economic differentiation are reduced. 
That idea was reaffirmed at the HNCC ASEAN 9 (Bali, Indonesia, October 2003), as shown in the ASEAN II Declaration of Harmony (also known as the Bamanoid Declaration II). Accordingly, ASEAN agreed to aim to form a self-strengthening ASEAN community by 2020 with 3 main pillars: political and security cooperation (ASEAN Security Community - ASC), economic cooperation (ASEAN Economic Community - AEC) and socio-cultural cooperation (ASEAN Socio-Cultural Community - ASCC). The decision to build an AEC in 2020 in the ASEAN Declaration of Harmony (Bali II Declaration II) states: creating a stable, prosperous and highly competitive ASEAN economic region where there is free movement of goods, services and investment, more free movement of capital flows, even economic development and poverty reduction, narrowing the socio-economic disparity.

In order to accelerate efforts to form the ASEAN Community, the 12th ASEAN Summit in Cebu, Philippines, in January 2007 decided to shorten the deadline for forming a Community, including the Economic Community, from 2020 to 2015. The conference also passed the Master Plan to build the ASEAN Economic Community on this occasion.

\section{LITERATURE REVIEW}

Four characteristics are simultaneously constituent elements of the AEC:

- A single market and common production facility, built through: Freedom of movement of goods; Freedom of service flow; Freedom of investment flow; Freedom of capital flow and Free movement of skilled labor.

- A competitive economic zone, built through policy frameworks on competition, consumer protection, intellectual property rights, infrastructure development, tariffs and e-commerce.

- Balanced economic development, implemented through SME development plans and implementation of integration initiatives to close the development gap in ASEAN.

- Integration into the global economy, conducted through close consultation in partner negotiations and in the process of participating in the global supply network (WTO).

The AEC's master plan for building by 2025 states: "Facilitating the movement of skilled workers and entrepreneurs. The goal is to facilitate the movement of skilled workers within ASEAN starting with MRAs that will allow those operating in 8 professional sectors to practice in other ASEAN countries through mutual recognition of quality and, where appropriate, through the implementation of the ASEAN Quality Reference Framework (AQRF) which is ams 
voluntary reference facility, to support the long-term learning process and strengthen the recognition and ASEAN Agreement on Human Mobility (MNP). These agreements are intended to facilitate the temporary movement across the borders of natural entrepreneurs and entrepreneurs carrying out activities on goods, services and investments."1

The 27th ASEAN Summit (November 21, 2015, in Kuala Lumpur) issued a Statement: " recognition of the completion of eight (8) Mutual Recognition Agreements (MRAs) on technical services, nursing services, architectural services, accounting services, dental services, medical services, geological measurement and professional tourism, contributing to facilitating the freedom of service sectors through the temporary migration of skilled professionals and workers", accordingly, the skilled workers of these 8 occupations will be shifted within the AEC. ${ }^{2}$

- $\quad$ Balanced economic development, implemented through SME development plans and implementation of integration initiatives to close the development gap in ASEAN.

- Integration into the global economy, conducted through close consultation in partner negotiations and in the process of participating in the global supply network (WTO).

The AEC's master plan for building by 2025 states: "Facilitating the movement of skilled workers and entrepreneurs. The goal is to facilitate the movement of skilled workers within ASEAN starting with MRAs that will allow those operating in 8 professional sectors to practice in other ASEAN countries through mutual recognition of quality and, where appropriate, through the implementation of the ASEAN Quality Reference Framework (AQRF) which is ams voluntary reference facility, to support the long-term learning process and strengthen the recognition and ASEAN Agreement on Human Mobility (MNP). These agreements are intended to facilitate the temporary movement across the borders of natural entrepreneurs and entrepreneurs carrying out activities on goods, services and investments." 3

The 27th ASEAN Summit (November 21, 2015, in Kuala Lumpur) issued a Statement: " recognition of the completion of eight (8) Mutual Recognition Agreements (MRAs) on technical services, nursing services, architectural services, accounting services, dental services, medical services, geological measurement and professional tourism, contributing to facilitating the freedom of service sectors through the temporary migration of skilled professionals and

\footnotetext{
${ }^{1}$ http://asean.mofa.gov.vn/thong-tin/46/ke-hoach-tong-the-cong-dong-van-hoa-xa-hoi-asean-2025.html

${ }^{2} \mathrm{http}$ //asean.mofa.gov.vn/thong-tin/41/tuyen-bo-chu-tich-cap-cao-asean-lan-thu-27.html

${ }^{3}$ http://asean.mofa.gov.vn/thong-tin/46/ke-hoach-tong-the-cong-dong-van-hoa-xa-hoi-asean-2025.html
} 
International Journal of Agriculture and Environmental Research

ISSN: 2455-6939

Volume: 07, Issue: 03 "May-June 2021"

workers", accordingly, the skilled workers of these 8 occupations will be shifted within the AEC. ${ }^{4}$

\section{RESULT}

The ASEAN economic community has the potential to lead to significant job growth in the region. But to reap these benefits, ASEAN member states must promote regional policies on labour migration: first, they must follow ambitious plans to freely move skilled workers, and secondly, develop a regional approach to migrant workers. low and medium skilled jobs will form the basis of permanent growth in the region. Labour migration has been a longstanding practice in Southeast Asia, in particular, the Philippines can be considered the prototype of a labor exporting country: After 40 years of labor export policy - initially considered a temporary measure - and creating a sophisticated state apparatus that serves Filipino foreigners and OFWs (Overseas Filipino Workers) on contracts temporarily, about ten percent of the population currently lives and works abroad. The remittances they send home have become an important source of income for families and the state as a loophole, but this dependence also has a major drawback: The labor market returning home still does not have enough job opportunities and even the current economic development is positive in the Philippines, it is believed to have a direct impact on growth or unemployment. While past migrants have often sought employment opportunities in Western countries and Gulf countries, migration within ASEAN has actually increased in recent years. The large economic disparity - a monthly salary of $\$ 119$ in Laos versus $\$ 3,547$ in Singapore - pushed the estimated number of ASEAN citizens residing in other ASEAN member states to about 6.5 million (up from 1.5 million in 1990). The actual number is probably significantly higher, since unusual migration is rampant in the region.

Considering the high level of bureaucracy and fees often required when using the official channels of the EAC, this seems like a reasonable choice from the point of view of migrants. But it makes them even more vulnerable to abuse and exploitation. Others have become unusual at the destination because they have overdue their visa. Even under normal programs, protection of migrants' rights may not be guaranteed, as destinations, such as Singapore, migrant workers are categorised into different categories: skilled workers are prioritized and may have the right to stay; migrants in low-skilled jobs can only receive temporary contracts; and domestic workers are completely excluded from labor law, since their occupation is not recognized as actual work. Labour migration within ASEAN is usually negotiated at the bilateral level and in the Non-Binding Memorandum of Understanding (MOU). Obviously, large economic disparities between countries (mainly the Philippines, Indonesia, Cambodia and Laos) và các quốc gia tiếp

\footnotetext{
${ }^{4}$ http://asean.mofa.gov.vn/thong-tin/41/tuyen-bo-chu-tich-cap-cao-asean-lan-thu-27.html
} 
nhận (chủ yếu là Malaysia và Singapore) and the choice of receiving countries that meet their migrant workers' needs through supply from many countries and often competitive countries leads to unevenly negotiated positions. This issue is believed to have some of the following causes:

\section{- Lack of job growth due to inadequate policy}

These factors will call for a regional framework to tackle labour migration. The ASEAN Economic Community (AEC) emphasizes the need for regional migration governance, as the anticipated prosperity of the community lies in the parts connected to migrant labour. According to the International Labour Organization (ILO) and the Asian Development Bank (ADB), the demand for skilled workers is growing but the greatest demand will continue to be for low- and medium-skilled jobs, in areas such as trade, transport and construction. This demand will most likely not be met by the domestic workforce, which reinforces the need for labour migration. In fact, models for six out of ten member countries predict up to 14 million additional jobs. There have been efforts to solve the problem at the regional level. The 2007 Declaration - Non-Binding - on protecting and promoting the rights of migrant workers is undoubtedly a turning point, but the proposed next ASEAN Framework Tool is still in the stages of an optional draft: countries of arrival and origin cannot agree on including family members and unusual migrants in the tool. Other initiatives, such as the establishment of the ASEAN Forum on Migrant Labour (AFML) in 2008 and the ASEAN Agreement in 2012, provided space for dialogue or summary of current regulations but to no existing results. In fact, the AEC overcomes insular and low-skilled labour migration and focuses on free trade flows in the region. A study by the Asia-Pacific Trade Research and Training Network (ARTNeT) points out: "Current policy even if fully implemented is not enough to achieve this." So far, ASEAN countries have agreed to facilitate visa issuance and employment, but only for professionals, those involved in cross-border trade and investment- mentally related activities.

As a result, the majority of the highly skilled workforce still faces a multitude of visa and employment restrictions in member countries, often demanding evidence that a position cannot be filled by a country. Furthermore, countries have completed mutual recognition agreements (MRA) in eight types of occupations, from engineering and architectural services to nursing and tourism professionals. But these make up only a small fraction (about one percent) of the total employment in the region and differ in their scope.

\section{- Lack of standards in recognition of qualifications}

ASEAN lacks standards in recognition of qualifications, undermining the free flow of skilled workers. Regulations in areas such as skills development, qualifications and certificates of 
dedication should be prioritised by the AEC. On the other hand, as the ILO points out, skills shortages and inappropriateness can hinder job development in ASEAN. There is also the risk of working on the table; for example, university graduates from the Philippines may prefer to work in low-skilled jobs abroad because of the huge pay gap. Measures that facilitate mobility, from more standardized skill recognition for savings and investment programs that transfer money to social safety, can help turn a user's brain into a regainable brain for countries of origin.

But the most pressing area is the governance deficit in regional migration beyond skilled labour. This includes protecting the rights of paperless migrants and employment contracts. In countries such as Malaysia regularly implement highly public deportation programs, while its economy actually relies on cheap and easily exploited foreign workers. Ratification and implementation of relevant UN and ILO conventions will be the first step in providing a working environment to consider the benefits of the migrant workforce.

\section{Figure 1: Differences in the shifting labor group in the EAC community}

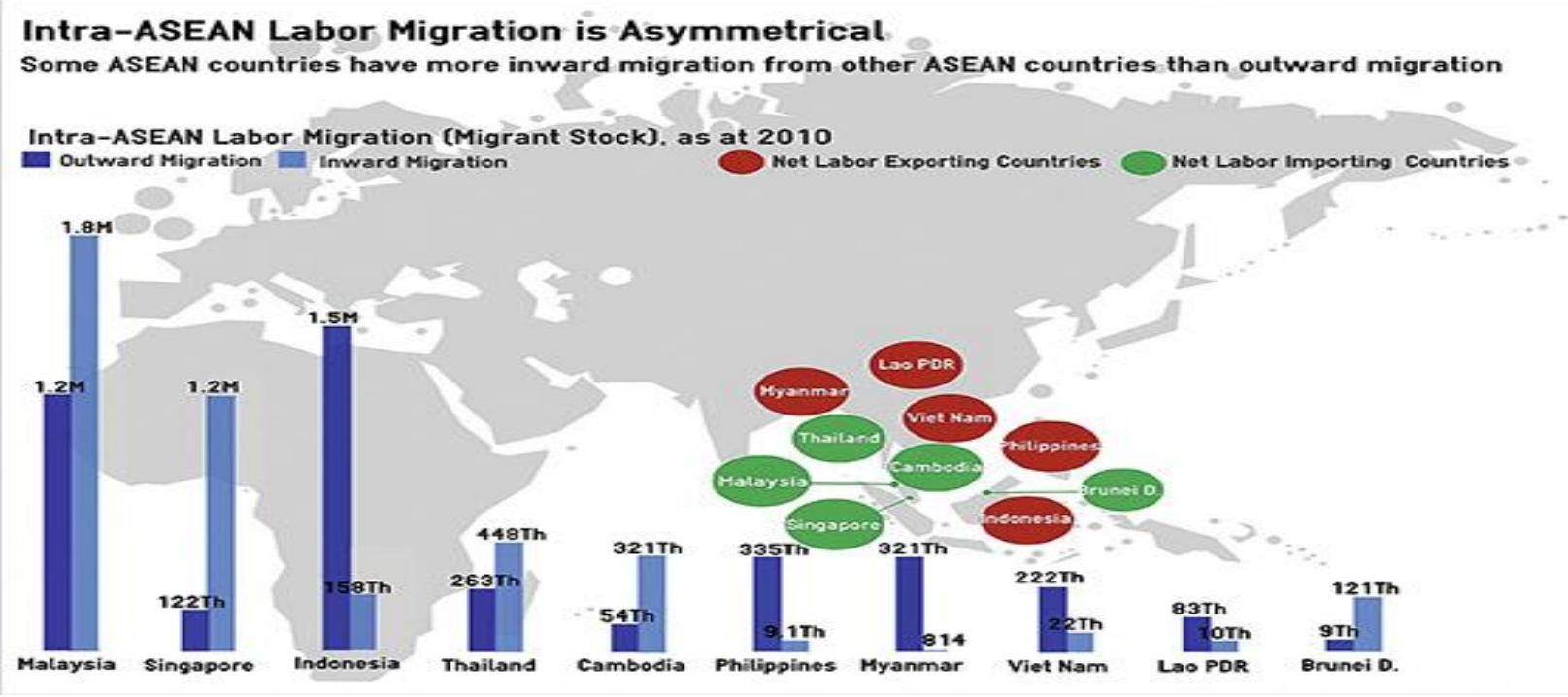

Source: IOM, 2010

The mobility of social and labour rights can be an engine for reducing abnormal migration. And strongly organized civil society in the region can serve as an important partner in migration governance in the region: in stark contrast to the draft of ASEAN countries, the initiation civil society expert group (TF- AMW) has compiled a comprehensive ASEAN-ASEAN Framework Tool on protection and promotion. Although ASEAN has explicitly stated its goal of promoting skilled labour movement, current policies are not only in the direction of the European Union, where freedom of movement is not hindered, but also less ambitious regional trade agreements 
such as the North American Free Trade Agreement (NAFTA) Caribbean Community (CARICOM). The lack of a cohesive regional framework, nationalist and protectional policies, and intermediary politics will hinder asean's movement of skilled workers. However, employers can still take advantage of policies that facilitate the hiring of skilled workers in certain areas to address the shortage of skilled workers frequently found in ASEAN countries.

Opportunities and challenges of Viet Nam's skilled workers when joining the Asean economic community

\section{Opportunity}

Viet Nam has the strongest change in the number of jobs in the AEC's 10 countries. In Viet Nam, the number of additional jobs added compared to the base scenario was 6.0 million, accounting for $9.5 \%$ of the total employment. Especially for skilled workers, free movement of labor in ASEAN will bring many positive benefits for workers. In the immediate future, with 8 labor professions in ASEAN free to move through equal skills recognition agreements, skilled and foreign-language workers will not only have more domestic jobs, but they will also have job opportunities in 10 in-bloc countries.

Figure 2: Estimated number of Vietnamese workers moving within ASEAN (Unit: person)

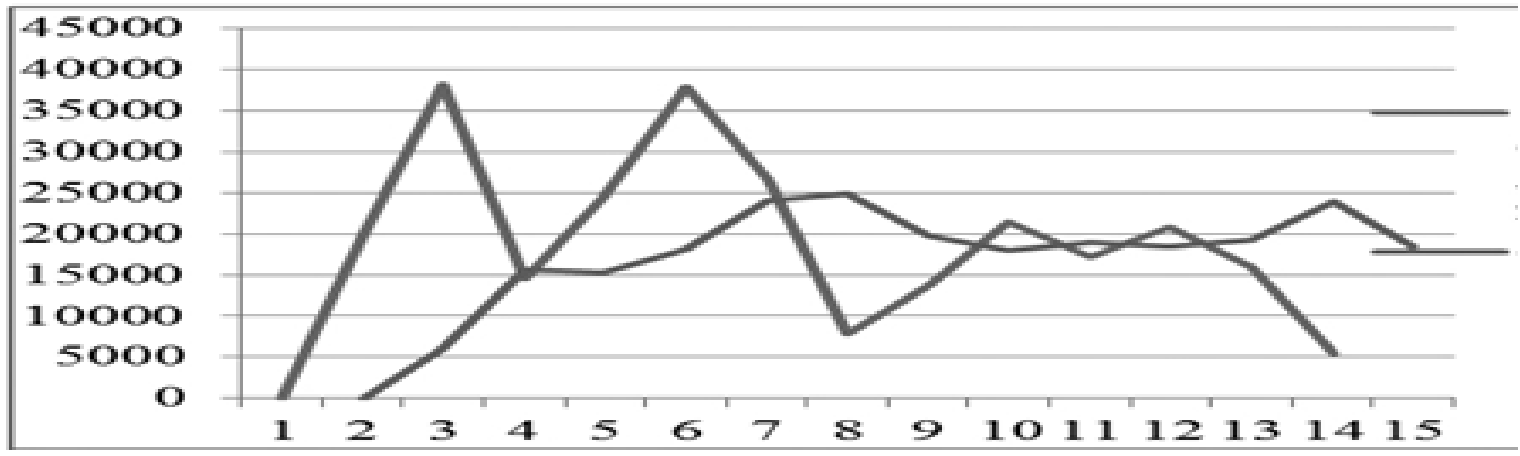

ILO Source (2017): Integration management towards greater prosperity and employment. ILO, Viet Nam.

Using the helmet leveling forecasting model, looking at figure 2, we can predict the number of Vietnamese workers moving within ASEAN by 2025 at about 10,996 workers. If skilled workers who previously wanted access to the foreign labour market had to go through organizations or governments, they now have direct access to more foreign businesses, thereby finding the most suitable job. Calculations by the ILO on employment changes under the AEC scenario compared to the base scenario show that Viet Nam has the strongest change in the number of jobs in both 
men and women. That reaffirms once again the opportunities of Vietnamese workers. In addition to having more job opportunities, skilled workers will be able to study and work in a more professional, dynamic, and high-pressure environment, thereby improving the necessary work skills.

\section{Challenge}

\section{Challenges from cultural differences}

Southeast Asia brings together most of the world's major religions. Countries have great respect for religious freedom, so workers moving to other countries will still be worshipped by their own religion. For the Vietnamese people, family plays a very important role. Although working in a dynamic environment with high salaries, without a policy to take families with you, it will cause concern for skilled workers. At that time, they were both faced with the environment, language, strange laws and under mental pressure when there were no families with them.

\section{Challenges from legal differences}

ASEAN is a he he he hemless bloc in terms of political system. The differences in institutions between asean countries are the basis for making legal differences. Therefore, the Labor Code of countries has different regulations for workers from abroad: on social security of each country, on the right to immigration some countries can offer an open-door policy, but some are very demanding - typically Singapore.Currently, the system of providing information to workers in Viet Nam has not really developed, the differences in laws, the difficulty of accessing and understanding the policies of the host country are a big challenge in moving skilled workers of our country.

\section{Professional challenges}

Of all the obstacles to labor, mobility skills, professional qualifications of labor are the biggest challenges: Skilled workers in our country, if considered by degree, are many but do not have the trust of society in general and employers in particular in their own country. Therefore, with the current technical qualifications, Vietnamese workers are difficult to meet the requirements of businesses from other ASEAN countries. Vietnam's qualifications framework is not yet complete to match the ASEAN Qualifications Framework, while other countries in the bloc have taken final steps in developing the National Qualifications Framework. Although workers are considered skilled in Viet Nam, it must be very difficult to improve all skills according to international standards. Viet Nam does not have a policy to recognize the capacity and 


\section{International Journal of Agriculture and Environmental Research}

ISSN: 2455-6939

Volume: 07, Issue: 03 "May-June 2021"

qualifications of workers experienced through labor and professional practices. Therefore, lowlevel people are experienced, able to handle situations, good work capacity but not recognized.

\section{DISCUSSED}

Currently the Vietnamese workforce is quite abundant, while economic conditions have not developed, employment in the industrial sector is still small, people's lives are still difficult, it is necessary to continue maintaining appropriate labor export policies. Bringing workers abroad must always be identified as a long-term solution, but it is necessary to develop a strategy according to the roadmap towards training and skilled labor exports that increase the value of labor. Step by step improve the quality of labor, gradually shifting from general labor export to high-level/professional labor export.

Continue to improve the laws and policies related to the issue of labor export in accordance with international and ASEAN commitments and regulations. On the one hand, it is necessary to supplement and amend missing or inappropriate mechanisms and policies such as: Investment policies to expand the market; Policies to support training and credit for employees to export; Credit policies for overseas workers, social insurance policies, policies to encourage remittance of money and goods back home, policies on receiving back after completing tasks.

Strengthening the state management of labor export and management of migrant labor, minimize illegal labor, or unauthorized labor lines, avoiding absolute empowering a single agency to manage and recruit labor can lead to corruption and negative. In order to effectively shift in-bloc labour, these displacement flows must be managed to limit the negative impact on the participating countries and the economy of the whole region. The management mainly focuses on controlling employees and relationships in the $\mathrm{OSH}$, ensuring a positive impact, without affecting the socio-political of the participating countries.

In terms of education and training, countries in the region have soon built a vocational training system with certificates according to regional and international standards. Thereby, employees have job opportunities in the AEC and difficult markets; improve the competitiveness between domestic workers and other AEC member countries. From the experience of other countries, Viet Nam needs to soon innovate the structure of vocational education, link training with the labor market and the participation of enterprises; promote international cooperation on vocational education. On that basis, employees are not only equipped with professional qualifications, knowledge but also knowledge about the working environment, social culture and legal system of the receiving country, so that when moving employees can integrate quickly. 
Develop policies to attract talents, improve the quality of domestic and export labor, so that Vietnamese workers can compete and ensure equal rights like local workers. Research and negotiate bilaterally to be recognized equivalent to the vocational skills level of Vietnamese workers with local workers and the AEC.

In order to create good conditions for in-bloc labour displacement, it is necessary to take the proactive role in protecting migrant workers. Some countries in the region do this well, bringing lessons to Viet Nam from the eradication of discrimination (domestic and foreign workers), universal social security and the creation of networks to receive and handle migrant workers' problems.

\section{CONCLUSIONS}

With ASEAN's goal of creating free movement of skilled workers, investors running businesses in the region may be surprised to see such limited movement between countries. In fact, companies that recruit highly skilled foreign workers often do not have the motive to hire employees from an ASEAN country compared to internationally. In most cases, hiring a foreign worker from another ASEAN member state requires following the same visa and work permit procedures as applies to other countries.

In addition, free movement of labour within ASEAN requires policy reforms and procedures synchronizity at both national and regional levels. For example, ASEAN still lacks a system of syncic visa updates for foreign businesses and skilled workers. Work permits and work permits remain subject to the principles and laws of the local countries. In the context of the current legal barriers, member countries are unlikely to change their policies soon to quickly realized the AEC's ideals for a skilled labour mobility free zone. In addition, disagreements around mutual recognition agreements as well as lack of synchronizity in the professional training system and certificates of member countries, practical application is risky work while the responsibility to recognize professional qualifications is part of the management mechanism of the state subordinates. The severe lack of awareness of AEC recognition and understanding agreements is a significant obstacle, limiting the socio-political motivations to accelerate this process. particularly the uneven level of development and regulation of ASEAN, which are also significant challenges for member states and Viet Nam in its ambition to expand its workforce to join the AEC community.

\section{REFERENCES}

ADB (2015). ASEAN 2030: Toward a Borderless Economic Community. Asian Development Bank, Manila, Philippines. 
Ngo Tuan Anh, Do Hai Dang (2015), Challenges for Vietnamese businesses when free trade agreements (FTA) were signed in 2015, The Year of the National Scientific Conference "Vietnam Economy 2015: Sparking growth motivation in the new context of integration", The National Economics University, Hanoi.

Nguyen Thi Hong Bich (2007) and Associates of The Institute of Social Sciences in the South, Labor Exports of some Southeast Asian countries - Experiences and lessons, Social Sciences Publishing House.

Pham Thi Thanh Binh (2010), International High-Professional Labour Movement: Trends and Impact, World Journal of Economic and Political Issues, No. 6 in 2010.

Nguyen Manh Cuong (2006), The issue of physical movement in the process of international integration, ministry-level topics, ministry of labor, war invalids and social affairs.

Nguyen Binh Giang (2011), International Labour Mobility, Social Sciences Publishing House, Hanoi.

Nguyen Van Ha (2013), Realization of the ASEAN economic community and impact on VietNam, Labour and Social Sciences, Hanoi.

Luu Van Hung (2008): Recent in-ASEAN labour movement and issues for Viet Nam, Southeast Asian Research Journal, September 2008 issue.

ILO (2012), Sustainable Job Search - Rights of Migrant Workers: Guidance for Trade Union Activists", ILO-Viet Nam National Cooperation Programme on Sustainable Employment 2012 - 2016.

ILO (2017), ASEAN Community: Integration Management towards Shared Prosperity and Better Employment. ILO, Viet Nam.

Hoang Kim Ngoc (2010), Solutions to improve the quality of labor resources to work abroad, Department of Overseas Labor, Ministry of Labor, War Invalids and Social Affairs.

Nguyen Ba Ngoc (2008), Cousted the number of jobs - problems of developing countries, Journal of Labor - Society, No. 343 - 344 - 345, October 2008.

Le Hong Nguyen (2009), Impact of international labour movement on Viet Nam's development in international integration, Journal of Economic Development, No. 24. 
Tran Thi Thuy (2015), Yearning of the National Scientific Conference "Vietnam Economics 2015: Sparking growth motivation in the new context of integration", National Economics University.

Mac Van Tien (2014), Opportunities and Challenges for Vietnamese Workers when joining the ASEAN economic community, Communist Magazine, No. 11/2014.

Vu Minh Tien, Duong Van Sao and associates (2006), Forecasting the impact on the lives, jobs of workers and trade union activities when Viet Nam joins WTO and NXB. Labour, Hanoi. 